EON • Volume 14, Issue 5 - November 2021

\title{
Antiracism Toolkits for \\ Scholarly Publishing \\ Address Long-Standing Inequities
}

Niccole Leilanionapaeaina Coggins, Jocelyn Dawson,

Damita Snow, CAE

Published on: Nov 17, 2021

License: Creative Commons Attribution 4.0 International License (CC-BY 4.0). 
In fall 2019, Niccole Leilanionapaeaina Coggins, Jocelyn Dawson, Melanie Dolechek, and Gisela Fosado initiated the Toolkits for Equity project to provide tools to address disparities around race in scholarly publishing. Front of mind were the 2018 Scholarly Kitchen posts “On Being Excluded: Testimonies by People of Color in Scholarly Publishing" (part I and part II) as well as surveys showing that our industry is disproportionately white (76\% per Lee and Low Books[1] and 91\% per Learned Publishing[2]). Both the surveys and the anonymous testimonies in the blog posts made it clear that within the scholarly publishing industry, Black, Indigenous, and People of Color (BIPOC) experience real harm and that there is an urgent need for change.

The Toolkits for Equity project was started to provide tools to construct an antiracist framework for scholarly publishing and to address some of the factors we saw as particularly pervasive in our industry:

1. Personal networks tend to be overwhelmingly racially homogenous so when we share job postings with only our networks, the problem compounds;

2. Historically publishing has relied on the labor of unpaid interns and low-paid entrylevel positions, precluding people without economic advantages; and

3. Hiring organizations prioritize applicants with previous industry experience (i.e., internships) rather than those with transferable skills.

While the antiracism toolkits include specific examples from scholarly publishing, we believe the toolkits' content can also be used by librarians, researchers, and others working throughout the scholarly communications ecosystem. The project includes antiracism toolkits for allies, for organizations, and for BIPOC working in scholarly publishing.

Our vision for the Toolkits for Equity project was to expand on the momentum of the numerous diversity, equity, and inclusion (DEI) committees that have started around our profession and give them a kickstart by providing tools and training materials. We also wanted to reframe the discussion. Although many DEI efforts to date have focused on pipeline programs and recruitment, these programs do not get at the root of the problem - the role of white supremacy in our workplace culture. We thought it was crucial to bring an explicitly antiracist framework to the discussion, to explicitly name 
white supremacy, and to talk frankly about the work that white people in our industry need to do to change workplace culture.

We based our antiracism framework on foundational training and resources from the Racial Equity Institute (EI). and Allies for Change. Over the past year, as we have presented our Antiracism Toolkit for Allies to different audiences, we have encountered the ever-changing face of white supremacy culture and have been reminded of a quote from the REI Phase 1 training workshop, "an organized lie is more powerful than disorganized truth." White supremacy is an organized lie, with people who are very invested in its continued existence, and we are all implicated in white supremacy because all of us have internalized its message. To eliminate the white supremacy in our society and in our culture, it will take devoting our lives to combating our internalized superiority or internalized oppression.

REI has a powerful "groundwater" analogy for racism and white supremacy. As explained in their white paper on this concept[]ㅡ (available as a downloadable PDF), if you were walking along a lake and you saw a dead fish floating in the water, you may think to yourself, "maybe it got caught in the weeds" or "maybe it ate something." Or perhaps you would think about another narrative that we often tell ourselves, "maybe that fish came from a one-parent household, or didn't go to the right fish school, or read the right fish books." Basically, the dead fish is floating in the lake because of something that the fish did. In the United States we are in the "fish-fixing" business; we are all about the individual fish. However, if you were walking along that same lake the next day and you saw a hundred dead fish floating in the water, you would think to yourself, "what is in the water?" Data, from a variety of disciplines across different spheres (economic, education, health, etc.), point to one clear overarching conclusion: racism affects outcomes. Racism and white supremacy are in the groundwater (culture and history) and it affects our lakes (systems and institutions) which affect the fish (individuals). And there is nowhere in the United States to escape the effects of racism.

\section{Antiracism Toolkit for Allies}

With the Antiracism Toolkit for Allies, which launched in August 2020 and is available as a PDF download, our goal was to create workplace communities where everyone thrives and in order to do that we need to make substantive change, not just checking a box or adding a few people as window dressing. Because scholarly communications is predominately white, white people doing their own work to recognize and dismantle 
white supremacy is critical for this substantive change to happen. The allies toolkit promotes awareness and understanding of white advantage as well as information about how to disrupt racism and begin to achieve our goal of workplace communities where everyone thrives. The 57-page document includes five key steps to becoming an ally, an abbreviated chronology of white supremacy, sample equity and inclusion programming, a sample list of affinity and inclusivity groups, and a list of recommended racial equity training organizations. We hope that the contents will help people gain acceptance as allies within scholarly publishing to accelerate progress toward a more inclusive and welcoming workplace community. For those of us working on developing antiracism toolkits for scholarly publishing, part of our work is to make the invisible visible. Not only is white supremacy a lie but it is also often invisible. So how do we make it visible? One way is to take a closer look at how white supremacy operates as a culture within our very workplaces.

\begin{tabular}{|c|c|c|}
\hline $\begin{array}{ll}\text { - } & \text { Perfectionism } \\
\text { - } & \text { Sense of urgency } \\
\text { - } & \text { Defensiveness } \\
\text { - } & \text { Quantity over quality } \\
\text { word }\end{array}$ & $\begin{array}{l}\text { - } \text { Only one right way } \\
\text { - } \quad \text { Paternalism } \\
\text { - Either/or thinking } \\
\text { - Power hoarding } \\
\text { - } \quad \text { Fear of open conflict }\end{array}$ & $\begin{array}{ll}\text { - } & \text { Individualism } \\
\text { - } & \text { Progress defined as } \\
& \text { bigger, more } \\
\text { - } & \text { Objectivity } \\
\text { - } & \text { The right to comfort }\end{array}$ \\
\hline
\end{tabular}

\section{Table 1. Characteristics of white supremacy culture. From Okun.[4]}

We highlight the work of antiracism educator and author Tema Okun in our toolkit. According to Okun's analysis[4]], the characteristics of white supremacy culture (Table 1) are everywhere and undergird the questions we have fielded after every presentation we have given on the allies toolkit. According to Okun, these characteristics in and of themselves are not necessarily toxic, however it is the way in which these characteristics are used that creates a toxic work environment. For example, perfectionism manifests as[ㄴ] $]$

- little or no appreciation expressed among people for the work that others are doing; when appreciation is expressed, it is often or usually directed to those who get most of the credit anyway;

- more common is to point out either how the person or work is inadequate;

- or even more common, to talk to others about the inadequacies of a person or their work without ever talking directly to them;

- mistakes are seen as personal, i.e. they reflect badly on the person making them as opposed to being seen for what they are - mistakes; 
- making a mistake is confused with being a mistake, doing wrong with being wrong;

- little time, energy, or money put into reflection or identifying lessons learned that can improve practice, in other words there is little or no learning from mistakes...;

- a tendency to identify what's wrong; little ability to identify, name, define, and appreciate what's right

Perfectionism pervades publishing - we have heard of resumes being tossed because of a typo, even for non-editorial jobs. And in an industry where we are always trying to do more in less time or for less money, urgency takes precedence. Rather than building in time for staff to learn about antiracism, organizations prioritize day-to-day work, forgetting how costly staff turnover is when a workplace is unwelcoming and inequitable. Okun suggests that the antidote is a culture of appreciation in which an organization takes time to make sure that people's work and efforts are appreciated[ㄴ]:

- develop a learning ... organization, where the stated expectation is that everyone will make mistakes and those mistakes offer opportunities for learning;

- create [an environment where people can recognize that] mistakes sometimes lead to positive results...

- separate the person from the mistake; when offering feedback, always speak to the things that went well before offering critical feedback ... ask for specific suggestions [for] how to do things differently when moving forward;

- realize that being your own worst critic does not actually improve the work, often contributes to low morale among the group, and does not help you or the group to realize the benefit of learning from mistakes.

\section{Antiracism Toolkit for Organizations}

The Antiracism Toolkit for Organizations is now available online. This toolkit, which launched in late August 2021, addresses topics such as what antiracist leadership looks like, what to do if you don't have a budget for antiracism/DEI work, how you can build internal structures for equity work, recruitment and retention, mentorship and sponsorship, and employee professional development, and how to measure success. We have also included an extensive resource list for further guidance.

One of the most positive results of this project has been the relationships that formed among our group of volunteers. Over 40 volunteers (writers, readers, copyeditors, illustrators, reviewers, etc.) had a hand in this project. This toolkit is a result of their 
hard work, level of engagement, and commitment to the mission behind the project. The project connected people working at large publishers like SAGE with those at small university presses and scholarly societies and brought together volunteers from both the United States and United Kingdom. We are pleased with the idea- and resource-sharing that has come about through these newly created relationships. This toolkit was led by Jocelyn Dawson and Damita Snow.

\section{What Does Success Look Like for This Project?}

A major goal from the start of this project was to create a culture shift in publishing: we want people to thrive in their respective organizations. We have provided some tools, case studies, and resources to assist with addressing current issues. Some initiatives can be put in place immediately, but we know that building understanding and changing culture will take time. We want people to read the toolkits, grab takeaways that will assist them in some way, and share these insights within their networks. It is a resource for everyone, and we want to hear from anyone who reads it about how they have used it (ㄹutytoolkits@.gmail.com). We did our best to present relevant case studies and statistics to make the information rich and easy to digest.

Success also means white people will do the work to understand their advantages and actively work on an individual level, a relationship level, and a community level to dismantle white supremacist culture and create an environment in which everyone will thrive. We want BIPOC publishers to feel seen, supported, valued, and to hold positions of power within our field. We want them to stay in the industry and feel that they belong there.

It is our hope to continue providing resources that will keep the conversations moving forward and expect that the relationships and connections that the project has fostered will continue to grow and advance these conversations as well.

\section{Partnerships}

We were fortunate to have the support of additional partners on the production of this toolkit. We partnered with PubPub, a collaborative publishing platform, for hosting and production support, and with George Washington University in Washington, DC. We used PubPub to facilitate collaboration and for their robust toolset for accessibility. We 
worked with the George Washington University Masters in Publishing Program for some of the editing of the guide.

The Toolkits for Equity are now under the umbrella of the Coalition for Diversity \& Inclusion in Scholarly_Communications (C4DISC), which started in 2017 to bring together various organizations within the scholarly communications industry to increase diversity, equity, inclusion, and accessibility in scholarly communications while valuing differences, welcoming diverse perspectives, learning from different communities, making space for marginalized voices, and eliminating barriers. C4DISC believes that we can accomplish more when we work together to pool our resources, both human and fiscal, to build equity, inclusion, diversity, and accessibility in scholarly communications.

C4DISC currently hosts the first two racism toolkits, for allies and for organizations. It is facilitating the development of additional materials: the Antiracism Toolkit for BIPOC (led by Alejandra Mejía and Kerry Webb), the Toolkit for Disability Equity, and the Language and Image Guidelines for Scholarly Communications. The Toolkit for Disability Equity will serve as a resource guide to "help people with disabilities within scholarly communications thrive at work" and "will aim to engage, enable and empower both people with disabilities and allies to advocate for themselves and each other at work, so that we can create more disability-confident working environments throughout the scholarly communications industry."[ㅁ] The Inclusive Language and Image Guidelines for Scholarly Communications "will assess current practices across the industry and will then develop guidelines to help all authors, editors, and reviewers recognize the use of language and images that are inclusive and culturally sensitive."[ㄷ] This resource is intended to be used as a tool for individuals, institutions, and publishers around the world. The goal of the working group is "to set an industry standard that promotes proactive inclusive writing habits" by "addressing the various forms of conscious/unconscious bias and discrimination currently found in published research.”[ $\underline{5}]$

As of July 2021, the Antiracism Toolkit for Allies has been downloaded over 3,500 times, has close to 10,000 page views and the information has been presented to over 1,000 individuals at conferences, workshops, and webinars. It is our hope and expectation that the toolkits and guides that follow will have an even greater reach. Like the existing toolkits, the upcoming toolkits will be free to download and will be published under a Creative Commons license in the hope that others might adapt the toolkit for their particular region or situation. 


\section{Citations}

1. Lee \& Low Books. Where is the diversity in publishing? the 2019 Diversity Baseline Survey results.

https://blog.leeandlow.com/2020/01/28/2019diversitybaselinesurvey $/$. Accessed September 12, 2021.

2. Greco, A.N., Wharton, R.M. and Brand, A. (2016), Demographics of scholarly publishing and communication professionals. Learned Publishing, 29: 97-101. https://doi.org/10.1002/leap.1017

3. Hayes-Greene, Deena, and Bayard P. Love. The Groundwater Approach: Building a Practical Understanding of Structural Racism. The Racial Equity Institute. 2018.

4. T. Okun. White supremacy culture - still here. https://drive.google.com/file/d/1XR 7M_9qa64zZ00_JyFVTAjmjVU-uSz8/view. Accessed September 18, 2021.

5. C4DISC. Working groups. https://c4disc.org/working-groups/. Accessed September 18, 2021. 